\title{
Hybrid PET/MRI insert: B0 field optimization by applying active and passive shimming on PET detector level
}

\author{
Jakob Wehner ${ }^{1 *}$, Bjoern Weissler ${ }^{2}$, Volkmar Schulz ${ }^{1,2}$ \\ From PSMR14: 3rd Conference in PET/MR and SPECT/MR \\ Kos Island, Greece. 19-21 May 2014
}

${ }^{1}$ Department of Physics of Molecular Imaging Systems, Institute for Experimental Molecular Imaging, RWTH Aachen University, Aachen, Germany
Combining PET and MRI into a hybrid device is challenging since both systems might influence each other. A typical interference problem of such a combined device is the distortion of the MRI's $B_{0}$ field distribution due to the material brought inside the MRI's FOV which is in particular challenging for small-bore PET-systems. High field homogeneity is needed for a good MRI acquisition in general as well as in certain applications. Typically, active shimming using dedicated coils is applied to improve the field homogeneity. However, these techniques are limited especially for localized distortion profiles with higher-order characteristics caused by PET/MRI inserts. As a consequence, we are exploring the potential application of shimming on PET detector level (for the Hyperion-II ${ }^{\mathrm{D}}$ PET/MRI insert), meaning that the distortion profile caused by PET modules is compensated using additional magnetic materials (passive shimming) and DC coils (active shimming). To explore the technique, $\mathrm{B}_{0}$ field measurements have been performed using a whole-body phantom in combination with the MRI body coil. An FFE sequence was used to measure distortion maps of DC loops and small magnetic objects (capacitors, ferrites). These distortion maps served as input for a software framework which has been written to perform the field optimization. The implementation was verified by measurements and fits were performed to extract characteristic parameters of the tested objects. Finally, the implemented software framework was used to homogenize a measured distortion map produced by a single PET module by superimposing distortion corrections from additional simulated materials. The resulting superimposed distortion map showed a significantly improved $B_{0}$ field map quality (reduced spectral width and improved homogeneity). The simulated susceptibility distribution will be applied on PET module level and tested in experiments. Results and details about this study will be presented at the conference.

Authors' details

'Department of Physics of Molecular Imaging Systems, Institute for Experimental Molecular Imaging, RWTH Aachen

University, Aachen, Germany. ${ }^{2}$ Philips Research Europe, Aachen, Germany.

Published: 29 July 2014

\section{SpringerOpen ${ }^{\circ}$}

(c) 2014 Wehner et al; licensee Springer This is an Open Access article distributed under the terms of the Creative Commons Attribution License (http://creativecommons.org/licenses/by/4.0), which permits unrestricted use, distribution, and reproduction in any medium, provided the original work is properly cited. 
doi:10.1186/2197-7364-1-S1-A15

Cite this article as: Wehner et al: Hybrid PET/MRI insert: BO field optimization by applying active and passive

shimming on PET detector level. EJNMMI Physics 2014 1(Suppl 1):A15.

Submit your manuscript to a SpringerOpen ${ }^{\circ}$ journal and benefit from:

- Convenient online submission

- Rigorous peer review

- Immediate publication on acceptance

- Open access: articles freely available online

- High visibility within the field

- Retaining the copyright to your article

Submit your next manuscript at $\boldsymbol{\wedge}$ springeropen.com 